\title{
Joint Dynamics Of The U.S. Treasury Maturity Rates: Policy Implications For Central Banks
}

Omid Sabbaghi, University of Detroit Mercy, USA

\begin{abstract}
This paper examines whether there is a direct relationship between yields of differing maturities for the U.S. Treasury market. The hypothesis that long horizon rates may help to predict future short horizon rates, in addition to short horizon rates helping to predict future long horizon rates, provides the motivation for the present study. The proposed inter-relationship between the different interest rates exhibits important implications for central bank policy-making. Employing a multivariate time-series analysis, we find that spreads in the short-term rate tend to rise (fall) in response to rises in prior short-term (long-term) rate spreads. Additionally, spreads in the long term rates tend to decrease in response to prior rises in the 1 year Treasury rate spread. Finally, positive impulse responses for long term spreads largely derive from shocks to shorter term maturity spreads, while shocks to longer term maturity rates result in gradual negative impulse responses for maturity rates of shorter horizons. In sum, this paper provides evidence of important feedback relationships across the maturity spectrum in the U.S. Treasury market. An understanding of the maturity rate dynamics is crucial for future central bank interventions and for the pricing of options and other related financial instruments.
\end{abstract}

Keywords: U.S. Treasury maturity rates; Vector autoregression; term structure; central bank policy

\section{INTRODUCTION}

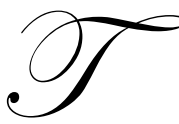

he relationship between the US Treasury yield to maturity and the term to maturity is known as the term structure of interest rates. Several hypotheses surround the determination of interest rates at distant horizons. The expectations hypothesis is one of the well-known in the empirical finance literature and theorizes that yields to maturity are determined solely by expectations of future short term interest rates. One of the main implications of the expectations hypothesis is that Treasury rates across different maturities are inter-related with one another in a dynamic manner. In particular, the expectations hypothesis suggests that current short-horizon rates exhibit important information content for future long term maturity rates.

This paper contributes to the empirical finance literature in numerous ways. First, this study examines the time-series behavior of the 1 year, 5 year, 10 year, and 20 year U.S. Treasury Constant Maturity Rates. In particular, this study tests the financial time series for stationarity by employing the statistical decision rule proposed by Kwiatkowski, Phillips, Schmidt, and Shin (1992), henceforth the KPSS test. The KPSS test differs from the usually applied Augmented Dickey Fuller in an important way: the null hypothesis of the KPSS test focuses on a time-series process that does not contain a unit root. In other words, the null hypothesis of the KPSS test is formulated in terms of a stationary process. Rejection of the null hypothesis implies non-stationary behavior.

Second, this study investigates the joint dynamics of the Treasury rates in a vector autoregression (VAR) framework. An evaluation of the Treasury rates using VAR methodology is vital for a variety of reasons. In contrast to univariate regressions, vector autoregressions allow for important cross-variable dynamics between the different maturity rates. For example, the expectations hypothesis suggests that the 20 -year rate depends on the history of the 1 year, 5 year, and 10 year rates, in addition to its own respective time-series history. Hence, the economic 
magnitude and statistical significance of the VAR coefficient estimates are important for the purposes of assessing predictive causality.

The VAR model in the present study is one of the first explorations of the information content of U.S. Treasury rates across different maturities. Specifically, the VAR model developed in this study relies on the historical time-series of the U.S. Treasury rates in predicting future rates: this paper tests whether or not there is a channel linking current and expected future Treasury rates. Campbell et al. (1997) argue that there is a direct relationship between yields of all maturities. Since the 20 year maturity rate results from compounding a series of expected future short-horizon rates and term premia, the 20 year rate may also contain information about future yields of shorter maturities. Thus, the hypothesis that long horizon rates may help to predict future short horizon rates, in addition to short horizon rates helping to predict future long horizon rates, provides the motivation for the present study.

Recent studies have modeled interest rates in a VAR framework. For example, Bianchi et al. (2009) employ a factor augmented VAR model for the United Kingdom Treasury yield data. The theoretical yields predicted by their VAR model tracks the actual U.K. Treasury yields with significant accuracy. Their study concludes that timevarying VAR models are consistent with the predictions of the expectations hypothesis. Using U.S. data, Brandt and Kavajecz (2004) implement a first-order VAR model in examining the daily dynamics of Treasury yields. The latter study concludes that price discovery exhibits an important role in understanding the behavior of the yield curve. Vereda et al. (2008) estimate VAR models that include macroeconomic variables and the term structure of interest rates using data from Brazil. Their analysis concludes that for the purposes of short-horizon forecasting, the presence of macroeconomic variables do not improve forecasts. Rather, the historical time-series observations of the different maturity rates are most important for forecasting rates in the short run.

Finally, this paper examines the dynamics of the estimated VAR model for Treasury maturity rates by using impulse response function analysis. In particular, impulse response analysis allows for a direct evaluation of ripple effects that may exist when the Federal Reserve adjusts a particular Treasury rate in a sudden manner. For example, it is interesting to examine whether a shock to the 1 year Treasury rate will contemporaneously affect the 5 year, 10 year, and 20 year Treasury rates.

The paper proceeds as follows. In Section 2, the data, variable definitions and empirical methodology surrounding the U.S. Treasury maturity rates are introduced. Section 3 presents summary statistics, VAR model estimates, impulse response functions, and a discussion of the empirical results. In Section 4, policy implications, concluding remarks and further directions for future research are presented. Figures and Tables are in the Appendix.

\section{DATA \& EMPIRICAL METHODOLOGY}

This study examines the time series behavior of the 1 year, 5 year, 10 year, and 20 year Treasury Constant Maturity rates at the weekly frequency. Several approaches are undertaken to understand the cross-variable dynamics between the different rates. The Federal Reserve Bank of St. Louis, which publishes U.S. interest rate and financial data, is the source of the data in this study. The weekly Treasury Constant Maturity Rate time series for the 1 year, 5 year, 10 year, and 20 year maturities are denoted by the vector $z_{t}=\left(z_{1 t}, \cdots, z_{4 t}\right)^{\prime}$, respectively. That is, the vector time series contains 4 components. We focus on the time period that ranges from January 1994 to May 2005.

Prior to the estimation of the vector autoregression (VAR) model, the individual Treasury rate series are tested for nonstationary behavior using the test proposed by Kwiatkowski et al. (1992). The test comprises of a timeseries regression model for Treasury rate with maturity of $i$ years, denoted $z_{i, t}$, and includes a time trend. Formally, the regression is given by:

$$
z_{i, t}=c+\mu t+k \sum_{i=1}^{t} \xi_{i}+\eta_{t}
$$


The disturbance terms $\eta_{t}$ are stationary and the $\xi_{i}$ terms are independent and identically distributed with an expected value of zero and a variance of 1 . The KPSS test examines the null hypothesis $H_{0}: k=0$ versus the alternative hypothesis $H_{A}: k \neq 0$. A rejection of the null hypothesis suggests that the time series process $z_{i, t}$ is nonstationary and that differencing is required in order to induce stationary behavior.

Following the outcomes of the KPSS tests, a vector autoregression (VAR) model is estimated for the appropriately differenced Treasury maturity rates. Let $z_{t}=\left(z_{1 t}, \cdots, z_{k t}\right)^{\prime}$ be a $k$-dimensional time series observed at equally spaced time points. Formally, the process $z_{t}$ follows a vector autoregressive model of order $p, \operatorname{VAR}(p)$, if:

$z_{t}=\phi_{0}+\sum_{i=1}^{p} \phi_{i} z_{t-i}+a_{t}$

where $\phi_{0}$ is a constant vector and $\phi_{i}$ are $k$ x $k$ matrices for $i>0,\left\{a_{t}\right\}$ is a sequence of iid Gaussian random vectors with mean zero and positive definite covariance matrix $\Sigma$, and $\phi_{p} \neq 0$.

In an $\mathrm{N}$-variable vector autoregression of order $p, \operatorname{or} \operatorname{VAR}(p)$, we estimate $\mathrm{N}$ different equations. That is, we estimate $\mathrm{N}$ linear regressions using the ordinary least squares estimation. In each equation, we regress the relevant dependent variable on $p$ lags of itself, as well as $p$ lags of every other variable. Thus the independent variables are the same in every equation: $p$ lags of every variable. The $\operatorname{VAR}(p)$ model can also be written as:

$z_{t}^{\prime}=x_{t}^{\prime} \beta+a_{t}^{\prime}$

where $x_{t}=\left(1, z_{t-1}^{\prime}, \cdots, z_{t-p}^{\prime}\right)$ is a $(\mathrm{kp}+1)-$ dimensional vector and $\beta^{\prime}=\left[\phi_{0}, \phi_{1}, \ldots, \phi_{p}\right]$ is a $k \mathrm{x}(k p+1)$ matrix. The maximum likelihood estimate of $\beta$ is given by:

$\hat{\beta}=\left[\sum_{t=p+1}^{n} x_{t} x_{t}^{\prime}\right]^{-1} \sum_{t=p+1}^{n} x_{t} z_{t}^{\prime}$

The present study focuses on several information criteria as a means of assessing the order of the vector autoregression model for the U.S. Treasury rates. In particular, this study uses the Akaike (1974), Hannan and Quinn (1979), and Schwarz (1978) Information Criteria. The interpretation of the information criteria is such that we select the order $p$ that minimizes the information criteria.

We interpret VAR dynamics through an analysis of the impulse response function. In particular, impulse response analysis allows for a unit innovation to a particular maturity series to affect the multivariate system. Consider, for example, the bivariate VAR(1) model in Eqns. (5) through (7):

$$
\begin{array}{ll}
z_{1 t}=\varphi_{11} z_{1, t-1}+\varphi_{12} z_{2, t-1}+\varepsilon_{1 t} & \varepsilon_{1 t} \sim W N\left(0, \sigma_{1}^{2}\right) \\
z_{2 t}=\varphi_{21} z_{1, t-1}+\varphi_{22} z_{2, t-1}+\varepsilon_{2 t} & \varepsilon_{2 t} \sim W N\left(0, \sigma_{2}^{2}\right) \\
\operatorname{cov}\left(\varepsilon_{1}, \varepsilon_{2}\right)=\sigma_{12} &
\end{array}
$$


In Equations (5) through (7), impulse response analysis quantifies the current and future effects that a unit shock to $\varepsilon_{i}$ exerts upon $z_{j}$ for all the possible combinations of $i$ and $j$. This is accomplished by examining the coefficients in the moving average representation of the process. In the present study, we adopt the normalization by the Cholesky factor (Hamilton 1994). Several attractive properties result as a consequence. One, the innovations of the normalized system are in standard deviation units. Two, the current innovations in the normalized representation exhibit non-unit coefficients. Finally, the Cholesky normalization achieves a zero covariance between the disturbances of the transformed system, and thus allows for the shocking of one variable in the isolation of the other variables.

The extent to which lags of the different maturity rates contain useful information for predicting future rates is embodied in the magnitudes of the VAR coefficient estimates. That is, predictive causality in the context of the VAR model dictates that the model's coefficient estimates are statistically distinguishable from zero in a joint manner. For example, if the 1 year maturity rate exhibits predictive causality for the 20 year maturity rate, we say that the 1 year maturity rate contains important information for predicting the 20 year maturity rate, and thus the coefficient estimate of the 1 year rate variable should be non-zero at conventional significance levels. In addition, this study uses an F-test to assess whether the coefficients on the lagged maturity rates are jointly zero. We examine these issues in what follows.

\section{RESULTS \& DISCUSSION}

\section{Descriptive Statistics}

Table 1 Panel A presents descriptive statistics for the levels of the U.S. Treasury Constant Maturity Rates, with selected rates exhibiting maturities of 1 year, 5 year, 10 year, and 20 year. The data is drawn from the FRED database at the Federal Reserve Bank of St. Louis and are sampled at the weekly frequency, ranging from January 1994 through May 2005.

As the term to maturity increases, Panel A demonstrates that the time-series average of the U.S. Treasury rate increases. This illustrates that, on average, the yield curve exhibits an upward sloping nature over this time period: the 1 year Treasury rate exhibits a sample average of 4.26 percent whereas the 20 year Treasury rate exhibits a higher sample average of 6.06 percent. This is in agreement with interest rate hypotheses that postulate higher rates accruing for more distant maturities. For example, the liquidity preference theory of the term structure argues that the source of the upward slope in the yield curve is attributed to the fact that shorter term U.S. Treasury securities exhibit a greater degree of liquidity relative to longer-term U.S. Treasury securities. Amihud (1986) argues in favor of a liquidity premium that is required to compensate investors for holding longer term securities with lower liquidity. In addition, Panel A presents the sample medians for the U.S. Treasury securities. Similar to the sample averages, the sample medians of the U.S. Treasuries tend to rise for more distant maturity rates.

In Panel A, the monotonic structure present for the sample time-series averages and medians extend to the remaining sample statistics, with the exception of the standard deviation. Specifically, the sample maxima and minima of the Treasury rates rise as the term to maturity increases. In contrast, however, the sample standard deviation decreases as the term to maturity increases. This suggests that the 1 year Treasury rate exhibits higher volatility relative to the 20 year U.S. Treasury rate. Specifically, the 1 year Treasury rate exhibits an unconditional standard deviation of 1.78 percent, whereas the 20 year Treasury rate exhibits a standard deviation of 89 basis points.

Figure 1 presents the time-series plots for the different U.S. Treasury maturity rates. Across the different maturities, Figure 1 suggests that the Treasury rate data tend to exhibit random walk behavior. Specifically, the time-series evidence suggests that the individual time series each contain a unit root. Thus, the U.S. Treasury maturity rates are integrated of order 1, i.e. I(1) processes.

The visual evidence of unit root behavior for the U.S. Treasury rates is formally confirmed in Table 1 Panel A. Specifically, Panel A presents the KPSS test statistics and their corresponding p-values for the U.S. Treasury 
maturity rates of interest: the test statistics are highly significant at the 1 percent level across the different maturity rates. Hence, the null hypothesis of stationary behavior is rejected for all of the U.S. Treasury rates. In other words, the Treasury rates exhibit non-stationary behavior across the maturity spectrum.

As a means of inducing stationarity, the Treasury rates are differenced. In this study, we refer to the differenced rate as the (time) spread in a given maturity rate: Panel B presents descriptive statistics. In Panel B, the time-series averages of the differenced series appear to be zero across the different maturities. Sample t-statistics for testing the null hypothesis of zero average rates are presented in parentheses: the t-statistics are insignificant at conventional levels, thereby suggesting that the time-series averages are statistically indistinguishable from zero. Similarly, sample medians are near zero across maturities. Thus, differencing has induced the time series data to be weakly stationary. This is formally confirmed when examining the KPSS test statistics and their corresponding pvalues for the different maturities. For each of the individual differenced series, we are unable to reject the null hypothesis of stationarity at conventional significance levels: 3 of the 4 KPSS p-values are greater than 0.10 while the remaining KPSS value is 0.08 .

Similar to Panel A, Panel B confirms that the unconditional standard deviation generally increases as the maturity term decreases. Figure 2 presents visual evidence of this observation. In particular, Figure 2 presents the time-series plots for the differenced rate series across the different maturities. Comparing the time-series plot of the differenced 5 year rate versus the differenced 20 year rate, we observe a higher degree of volatility for the 5 year rate spreads. Interestingly, the differenced 1 year rate exhibits a standard deviation that is relatively lower.

\section{Vector Autoregression Analysis}

We proceed to estimate a vector autoregression model for the Treasury maturity rates. A close examination of several information criteria is warranted when assessing the order of a vector autoregression. Table 2 presents realized information criteria for the differenced Treasury yield data. In particular, realized values for the Akaike (1974), Hannan and Quinn (1979), and Schwarz (1978) information criteria are provided. While the Akaike Information Criterion suggests a VAR model of order 3, both the Hannan and Quinn and Schwarz Information Criteria suggest a VAR model of order 1. Thus the present study, in agreement with the Hannan and Quinn and Schwarz Information Criteria, estimates a VAR model of order 1 to the Treasury rate data.

Table 3 presents the coefficient estimates of the VAR(1) model. The coefficients are estimated by maximum likelihood. In particular, an ordinary least squares regression is estimated for each of the Treasury spreads, with lags of the different spreads included as a means of allowing for cross-variable dynamics.

Several important observations are present in Table 3. Equation-by-equation, the F-statistics are highly significant at the 1 percent level. This suggests that all of the lagged maturity rates are jointly important in explaining the time-series variation for a given maturity rate. Econometrically, we reject the null hypothesis that the VAR coefficient estimates are jointly equal to zero. Thus, the inclusion of different maturity rates is vital for the purposes of explaining the time-series variation of a given Treasury maturity rate, and suggests that there are important feedback relationships.

While the F-test statistics suggest that the inclusion of all of the maturity rates is important, the decreasing nature of the $\mathrm{R}^{2}$ values across the maturity spectrum suggests that the goodness of fit monotonically decreases for longer-term maturity rates. Thus, the explanatory power of the different maturity rates decreases as the time to maturity increases.

In Table 3, we observe that the most important variables for explaining the time-series variation in the differenced 1 year Treasury rate are first-order lags of the differenced 1 year and 20 year Treasury rates. In particular, the coefficient estimate for the first-order lag of the differenced 1 year rate is positive and statistically significant at the 1 percent level. This suggests that the spread in the 1 year rate increases in response to prior positive changes of the 1 year rate spread. Specifically, the coefficient estimate suggest that the spread in the 1 year Treasury rate increases by about 25 basis points for a percent increase in the lagged 1 year Treasury spread. Thus, spreads in the short-term rate tend to rise in response to rises in prior short-term rate spreads. 
In contrast to the 1 year rate, the 20 year Treasury spread exerts a negative effect upon the conditional dynamics of the 1 year maturity spread. In addition, the lagged 20 year rate is significant at the 5 percent level, suggesting that it is less important relative to the 1 year rate. The realized negative coefficient suggests that positive changes in the 20 year Treasury rate spread are associated with negative future changes in the 1 year rate spread. Specifically, the coefficient estimate of -0.35 suggests that the differenced 1 year Treasury rate decreases by about 35 basis points for every percent increase in the lagged differenced 20 year Treasury rate. Hence, short-term spreads tend to fall in response to rises in prior long-term spreads.

Similar patterns exist for the 5 year and 10 year maturity rates. That is, spreads in each maturity rate tends to depend positively on its respective past history and negatively with respect to the historical 20 year spread. However, similar to the $\mathrm{R}^{2}$ pattern, it is important to note that the statistical significance of the explanatory variables tends to dissipate. For example, while the differenced 5 year Treasury rate depends positively on its respective timeseries lag and negatively on the lagged, differenced 20 year rate, the VAR coefficient estimates are statistically significant at the 10 percent level. When examining the dynamics of the 10 year rate, we find evidence of marginal significance at the 10 percent level.

The dynamics of the 20 year Treasury maturity rate differ from the behaviors of the 1 year, 5 year, and 10 year Treasury rates. In particular, the sole variable that exhibits individual statistical significance is the lagged change in the 1 year Treasury rate. Specifically, the coefficient on the differenced 1 year Treasury rate exhibits an economic magnitude of -0.14 and is statistically significant at the 10 percent level. This suggests that positive changes in the lagged 1 year rate are associated with subsequent negative changes in the 20 year rate. Specifically, a one percent increase in the differenced 1 year rate tends to be associated with a subsequent 14 basis point decrease in the differenced 20 year rate. Similarly, the 5 year and 10 year Treasury rates exhibit negative coefficient estimates on the lagged, differenced 1 year Treasury rate. Thus spreads in the long term Treasury rates tend to decrease in response to prior rises in the 1 year Treasury rate spread.

\section{Impulse Response Analysis}

To better understand the dynamics of the estimated VAR model, impulse response functions are plotted in Figures 3 through 6 . The impulse response function conveys dynamic properties of the estimated vector autoregression and exhibits important implications for forecasting interest rates. Specifically, the impulse response analysis conveys the extent to which the different maturity rates are affected with a one-standard deviation shock to a specific maturity rate in isolation.

Figure 3 presents the impulse response functions for our VAR model when a one-standard deviation shock is applied to the differenced 1 year Treasury Constant Maturity Rate. For each of the different maturities, the impulse response is positive and decays in a slow, monotonic fashion. Thus shocks to the 1 year Treasury rate, in isolation, lead to contemporaneous positive shocks for all of the maturity rates. This suggests the presence of a ripple effect that resonates from central bank interventions of the 1 year rate. Hence, a change in the expected 1 year rate leads to immediate positive changes in the expected 5 year, 10 year, and 20 year rates.

Figures 4 through 6 present the impulse response functions that result from one-standard deviation shocks to the differenced 5 year, 10 year, and 20 year Treasury rates, respectively. Interestingly, shocks to a given Treasury rate spread yield positive impulse responses for maturity rates of equal or greater horizons. For example, in Figure 4, a one-standard deviation shock to the differenced 5 year Treasury rate positively affects the spreads in the 5 year, 10 year, and 20 year maturity rates in a contemporaneous manner. Similarly, in Figure 5, a one-standard deviation shock to the differenced 10 year rate leads to positive impulse responses for the 10 year and 20 year differenced maturity rates. Hence, positive impulse responses for long term spreads largely derive from shocks to shorter term maturity spreads.

Finally, Figures 5 and 6 provide visual evidence that shocks to longer term maturity rates result in gradual negative impulse responses for maturity rates of shorter horizons. For instance, in Figure 5, a one-standard deviation shock to the 10 year Treasury rate spread results in a one-period ahead negative impulse response for both the differenced 1 year and 5 year Treasury rates. Similarly, a one-standard deviation shock to the differenced 20 year 
Treasury rate yields gradual negative impulse responses for the differenced 1 year, 5 year, and 10 year maturity rates. Thus, the evidence further highlights the presence of feedback relationships that results from shocks to longer term maturity rates. In other words, the impulse response function analysis suggests that the historical time series of the different maturity rates are interrelated with one another and exhibit important contemporaneous cross-variable dynamics.

\section{POLICY IMPLICATIONS \& CONCLUDING REMARKS}

Our results exhibit important implications for practitioners and central bank authorities. From a modeling perspective, our findings suggest that the history of each maturity rate can further improve upon our understanding of interest rates as a multi-dimensional system. In particular, maturity rates cannot be examined separately from one another. Such requires multivariate econometric and statistical models to assess the joint relationships.

The estimated VAR dynamics and impulse response functions provided in this study are crucial for designing effective policy decisions for central banks. Intuitively, the results suggest that the maturity rates are related to one another in important ways, and that effective interest rate adjustments should consider ripple effects. Specifically, well-designed adjustments to longer-term rates, such as the 20 year rate, may strategically achieve desired outcomes for short-run rates, in addition to short-run rates affecting longer term rates.

This study reports several important findings. First, using the stationarity tests of Kwiatkowski et al. (1992), the levels of the U.S. Treasury Constant Maturity Rates are found to be non-stationary across the maturity spectrum. The application of the KPSS test in this study differs from prior research that relies on augmented Dickey-Fuller tests in testing for unit roots. The KPSS tests suggest the presence of unit roots in the U.S. Treasury rate data. As a result, we conduct a VAR analysis on the differenced maturity rate series.

Second, a VAR model of order 1 is estimated for the maturity rate spreads over the 1994 through 2005 time period. The economic magnitudes of the VAR coefficient estimates suggest the presence of feedback relationships among the different maturity rates. In particular, spreads in the short-term rates tend to rise in response to rises in prior short-term spreads and tend to fall in response to rises in prior long-term spreads. In addition, the 20 year rate exhibits conditional dynamics that are different from the 1 year, 5 year, and 10 year rates. Specifically, spreads in the 20 year rate tend to fall in response to rises in the lagged 1 year rate spread and remains unaffected with its own respective time-series history. Finally, it is shown that the explanatory power of the different maturity rates decreases as the dependent variable's time to maturity increases.

Third, this study conducts an impulse response analysis on the basis of the estimated VAR(1) model. The impulse response functions demonstrate the presence of ripple effects that resonate from shocks to the short-term and long-term maturity rates. Specifically, it is shown that positive impulse responses for long term rate spreads stem from shocks to shorter term maturity rate spreads. Importantly, gradual negative impulse responses for shorter term rates stem from shocks to the differenced 10 and 20 year maturity rates.

Several avenues exist for further research. First, the vector autoregression model in the present study could be augmented to include moving average components. That is, a vector autoregressive moving average (VARMA) process may provide additional insights into the conditional dynamics of the U.S. Treasury Constant Maturity rates. However, building a VARMA model for the U.S. Treasury rates requires careful attention. In particular, there exist identification issues for VARMA models. That is, VARMA models may not be uniquely defined. Two approaches could be undertaken in discerning a VARMA model for the U.S. Treasury rate data. Specifically, the Kronecker index and scalar component model approaches may be used to structurally specify a VARMA model for the U.S. Treasury rate data (Tsay 2010).

Future work could also examine the volatility persistence of the differenced U.S. Treasury rates. In particular, volatility persistence across the maturity structure could be modeled in a GARCH framework. The GARCH model, proposed by Engle (1982) and Bollerslev (1986), provides a natural channel to model the conditional volatility of the differenced maturity rates. Recent studies have investigated various forms of such volatility dynamics. For example, Dungey et al. (2009b) present evidence in support of asymmetric response when 
examining the volatility of US Treasures across the maturity structure. Similarly, Jacobs and Karoui (2009) examine affine term-structure models in studying the conditional volatility dynamics for the U.S. Treasury market. Hughes et al. (2007) provide empirical evidence in support of U-shaped intraday volatility patterns for the U.S. Treasury bill market. Finally, Dungey et al. (2009a) provide evidence of jumps and co-jumps when examining the volatility dynamics of U.S. Treasury prices. The time-varying volatility of U.S. Treasury securities exhibit important implications for the pricing of options and other related financial instruments. These topics are left for future research.

\section{AUTHOR INFORMATION}

Dr. Omid Sabbaghi is Assistant Professor of Finance in the College of Business Administration at the University of Detroit Mercy. He received both his Ph.D. and M.B.A. from the University of Chicago's Booth School of Business, where he studied finance and econometrics. He earned his Bachelor of Arts degrees from the University of California-Berkeley with majors in Economics, Statistics, and Applied Mathematics. Dr. Sabbaghi's areas of research include portfolio management, volatility in financial markets, financial econometrics, and risk management. He lectures in courses such as Investments, Advanced Investments, and Corporate Finance.

\section{REFERENCES}

1. Akaike, H. (1974), “A new look at the statistical model identification,” IEEE Transactions on Automatic Control A19, 716-723.

2. Amihud, Y. (1986), “Asset pricing and the bid-ask spread," Journal of Financial Economics 17, 223-249.

3. Bianchi, F., Mumtaz, H., and Surico, P. (2009), "The great moderation of the term structure of UK interest rates," Journal of Monetary Economics 56, 856-871.

4. Bollerslev, T. (1986), "Generalized Autoregressive Conditional Heteroskedasticity,” Journal of Econometrics 31, 307-327.

5. Brandt, M.W., and Kavajecz, K.A. (2004), "Price Discovery in the U.S. Treasury Market: The Impact of Orderflow and Liquidity on the Yield Curve," Journal of Finance 59, 2623-2654.

6. Campbell, J.Y., Lo, A.L., and MacKinlay, A.C. (1997), The Econometrics of Financial Markets, Princeton University Press, Princeton, NJ.

7. Dickey, D.A., and Fuller, W.A. (1979), "Distribution of the Estimators for Autoregressive Time Series with a Unit Root," Journal of the American Statistical Association 74, 427-431.

8. Dungey, M., McKenzie, M., and Smith, L.V. (2009a), "Empirical evidence on jumps in the term structure of the US Treasury Market," Journal of Empirical Finance 16, 430-445.

9. Dungey, M., McKenzie, M., and Tambakis, D.N. (2009b), "Flight-to-quality and asymmetric volatility responses in US Treasuries," Global Finance Journal 19, 252-267.

10. Engle, R.F. (1982), “Autoregressive Conditional Heteroskedasticity with Estimates of the Variance of U.K. Inflation," Econometrica 50, 987-1008.

11. Hamilton, J.D. (1994), Time Series Analysis, Princeton University Press, Princeton, NJ.

12. Hannan, E. J., Quinn, B. G. (1979), "The determination of the order of an autoregression," Journal of the Royal Statistical Society B41, 190-195.

13. Hughes, M.P., Smith, S.D., and Winters, D.B. (2007), "An empirical examination of intraday volatility in on-the-run U.S. Treasury bills," Journal of Economics and Business 59, 487-499.

14. Jacobs, K., and Karoui, L. (2009), "Conditional Volatility in Affine Term Structure Models: Evidence from Treasury and Swap Markets," Journal of Financial Economics 91, 288-318.

15. Kwiatkowski, D., Phillips, P.C.B., Schmidt, Y., and Shin, Y. (1992), "Testing the Null Hypothesis of Stationarity Against the Alternative of a Unit Root," Journal of Econometrics 54, 159-178.

16. Schwarz, G. (1978), "Estimating the dimension of a model," Annals of Statistics 6, 461-464.

17. Tsay, R.S. (2010), Analysis of Financial Time Series, John Wiley \& Sons, New York, NY.

18. Vereda, L., Lopes, H., and Fukuda, R. (2008), "Estimating VAR models for the term structure of interest rates," Insurance: Mathematics and Economics 42, 548-559. 


\section{APPENDIX}

Figure 1

This figure presents the time-series plots for the 1 year, 5 year, 10 year, and 20 Year U.S. Treasury Constant Maturity Rates at the weekly frequency. The sample data is from the FRED database of the Federal Reserve Bank of St. Louis and ranges from January 1994 through May 2005.

Figure 2

This figure presents the time-series plot for the differenced 1 year, 5 year, 10 year, and 20 Year U.S. Treasury Constant Maturity Rates at the weekly frequency. The sample data is from the FRED database of the Federal Reserve Bank of St. Louis and ranges from January 1994 through May 2005.


Differenced 10 year US Treasury Constant Maturity Rate



Differenced 20 year US Treasury Constant Maturity Rate

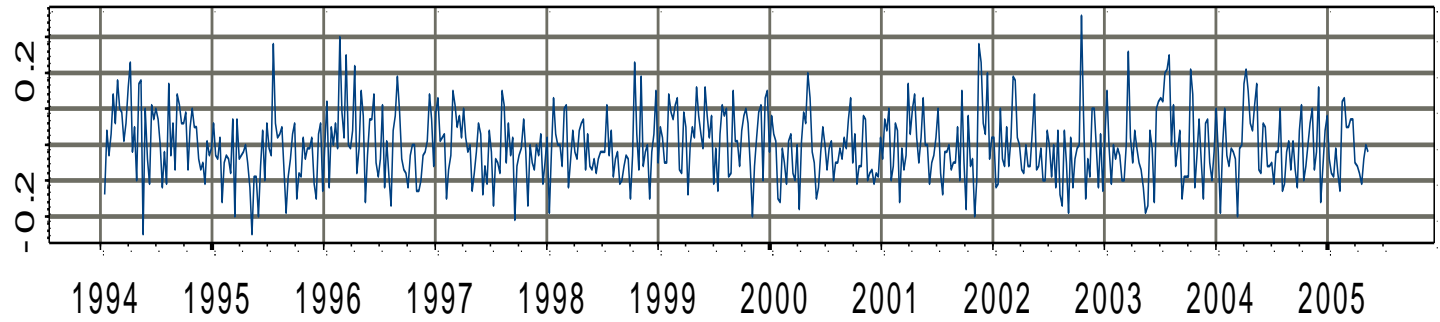


Figure 3

This figure presents the impulse response functions when applying a one-standard deviation shock to the differenced 1 year U.S. Treasury maturity rate. A VAR model of order 1 is estimated for the differenced series of the 1 year, 5 year, 10 year, and 20 Year Treasury Constant Maturity Rates at the weekly frequency. The sample data is from the FRED database of the Federal Reserve Bank of St. Louis and ranges from January 1994 through May 2005.

\section{Orthogonal Impulse Response from Treasury1YR}

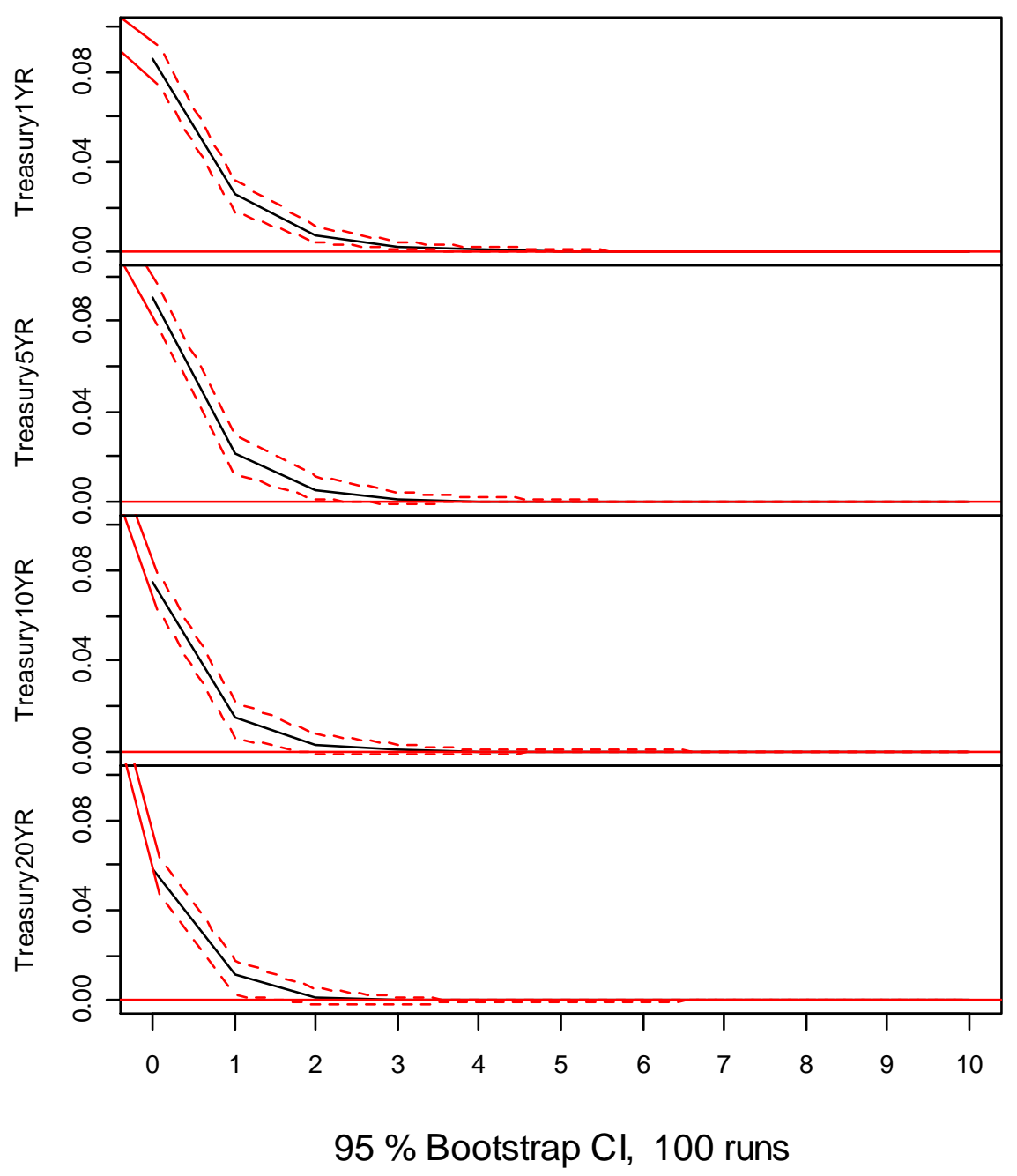


Figure 4

This figure presents the impulse response functions when applying a one-standard deviation shock to the differenced 5 year U.S. Treasury maturity rate. A VAR model of order 1 is estimated for the differenced series of the 1 year, 5 year, 10 year, and 20 Year Treasury Constant Maturity Rates at the weekly frequency. The sample data is from the FRED database of the Federal Reserve Bank of St. Louis and ranges from January 1994 through May 2005.

\section{Orthogonal Impulse Response from Treasury5YR}

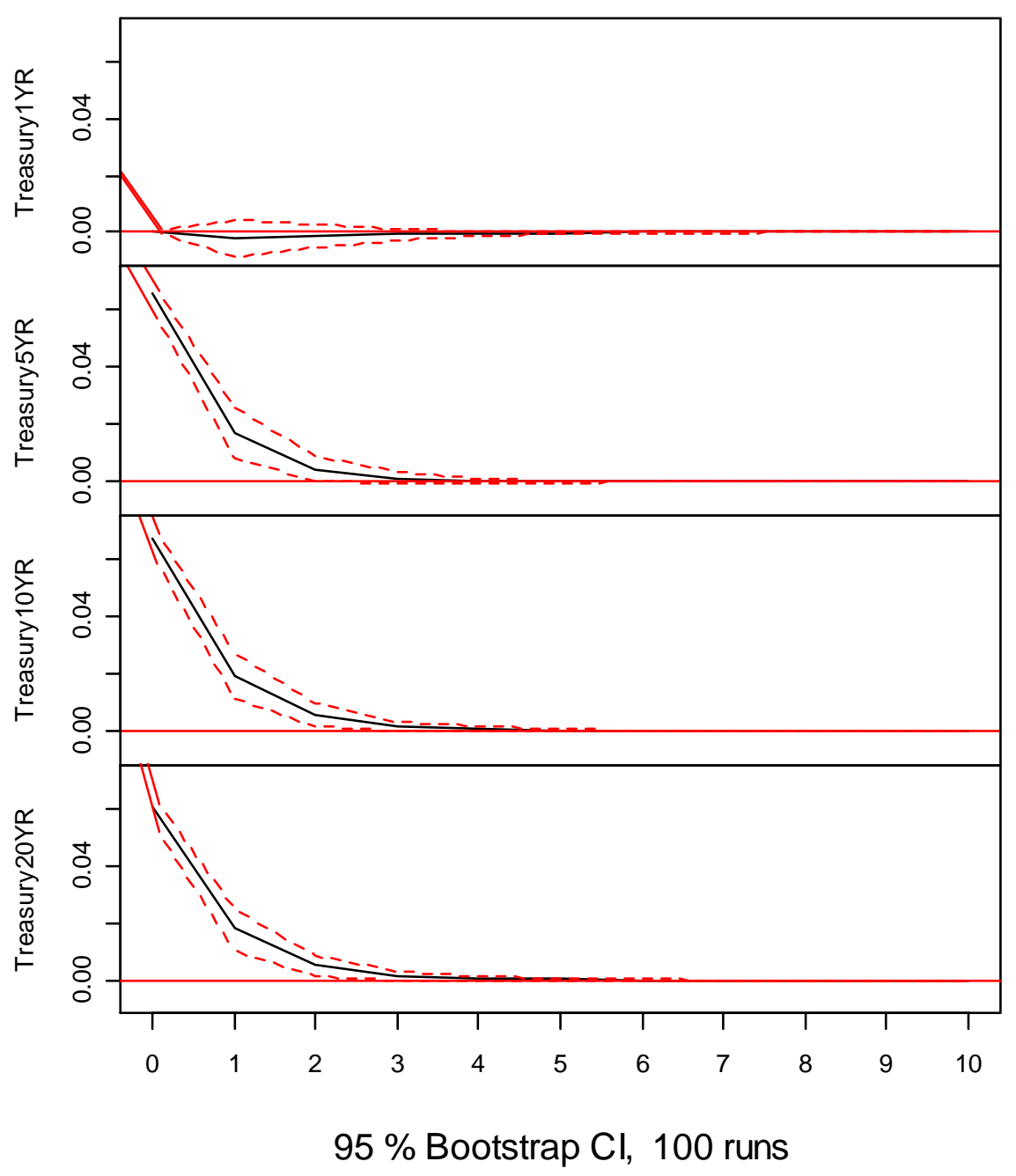


Figure 5

This figure presents the impulse response functions when applying a one-standard deviation shock to the differenced 10 year U.S. Treasury maturity rate. A VAR model of order 1 is estimated for the differenced series of the 1 year, 5 year, 10 year, and 20 Year Treasury Constant Maturity Rates at the weekly frequency. The sample data is from the FRED database of the Federal Reserve Bank of St. Louis and ranges from January 1994 through May 2005.

\section{Orthogonal Impulse Response from Treasury10YR}

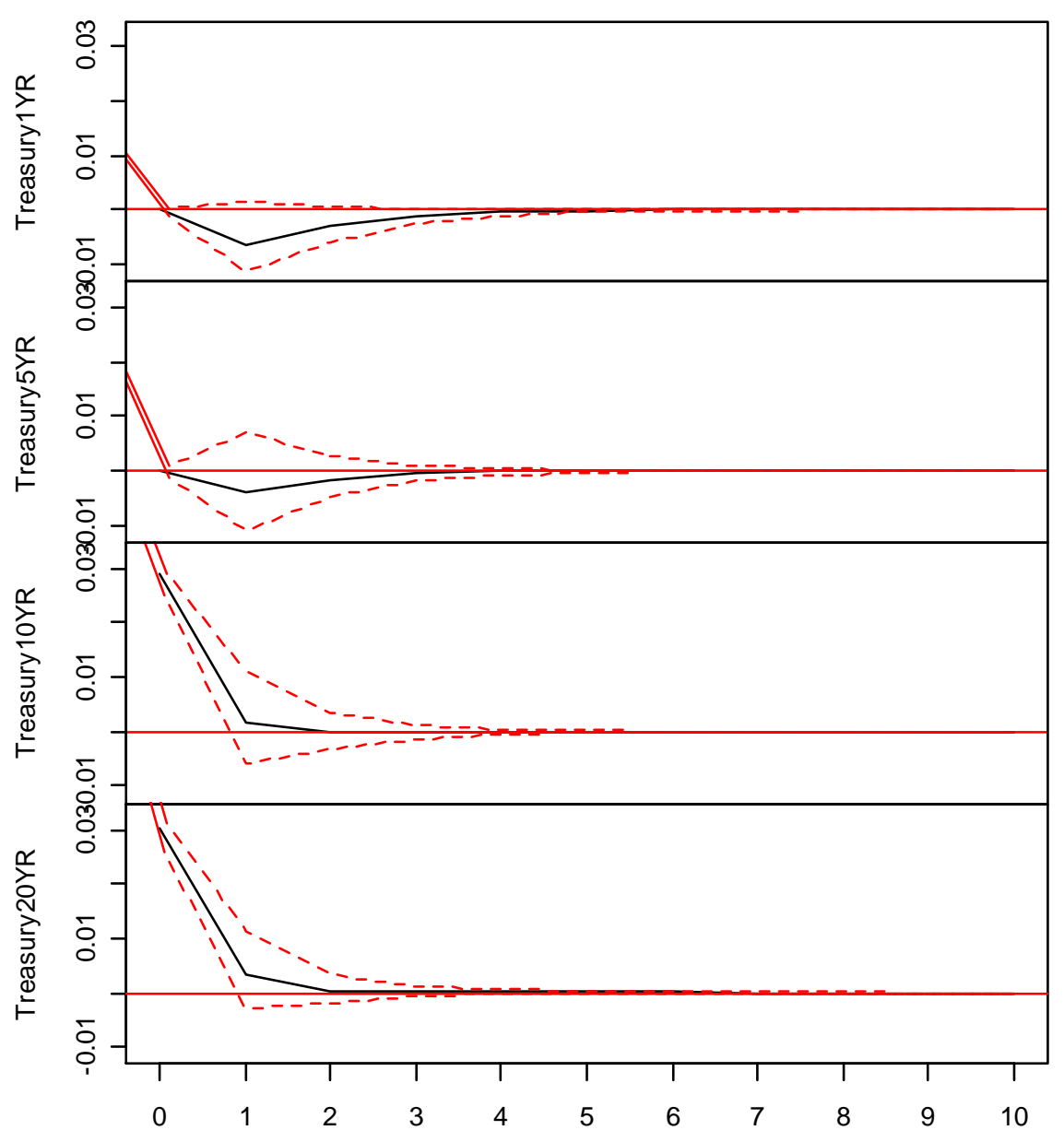

$95 \%$ Bootstrap Cl, 100 runs 
Figure 6

This figure presents the impulse response functions when applying a one-standard deviation shock to the differenced 20 year U.S. Treasury maturity rate. A VAR model of order 1 is estimated for the differenced series of the 1 year, 5 year, 10 year, and 20 Year Treasury Constant Maturity Rates at the weekly frequency. The sample data is from the FRED database of the Federal Reserve Bank of St. Louis and ranges from January 1994 through May 2005.

\section{Orthogonal Impulse Response from Treasury20YR}

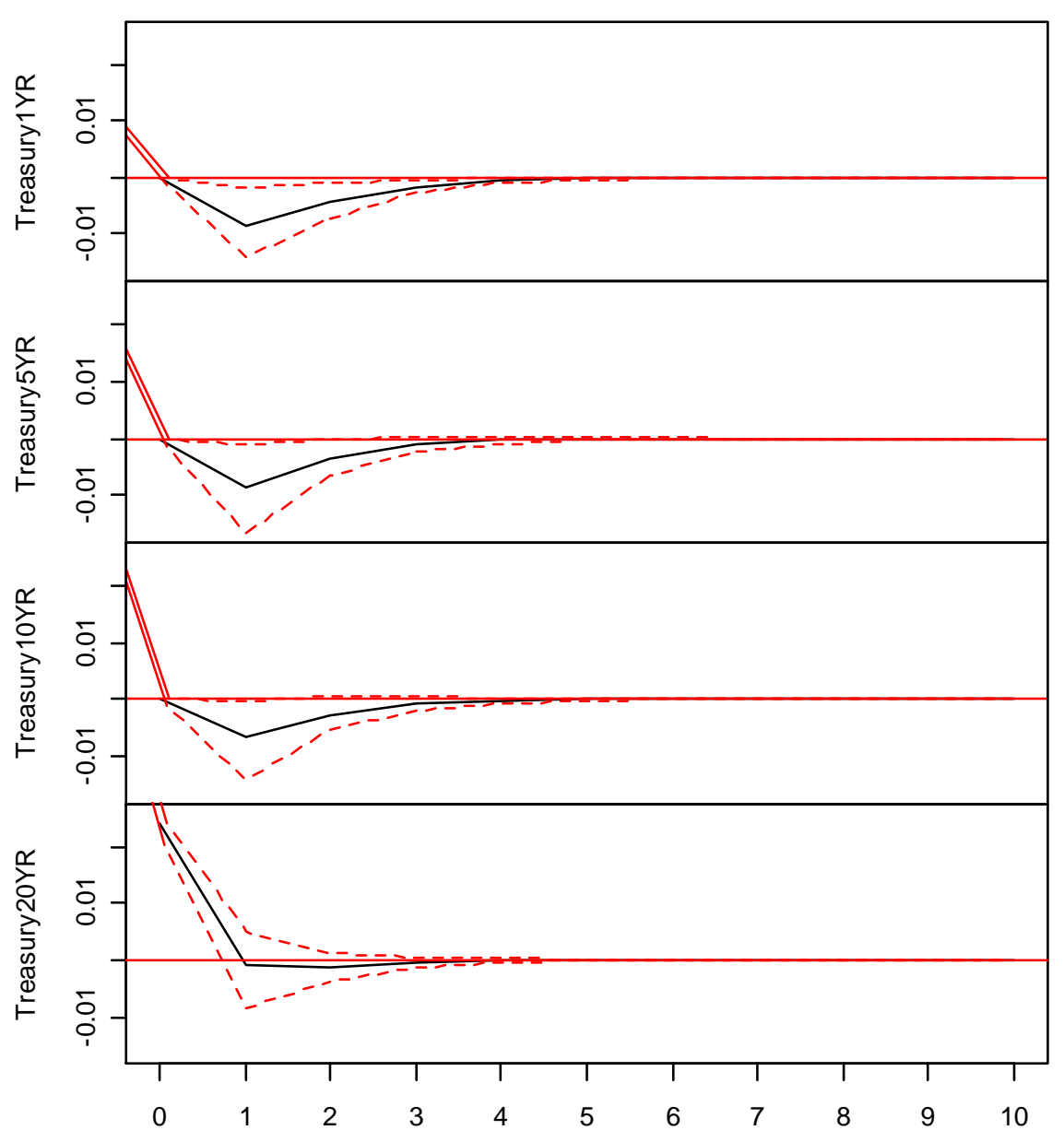

$95 \%$ Bootstrap Cl, 100 runs 
Table 1

Panel A presents descriptive statistics for the levels of the 1 year, 5 year, 10 year, and 20 year U.S. Treasury Constant Maturity Rates at the weekly frequency. Panel B presents descriptive statistics for the differenced series of the 1 year, 5 year, 10 year, and 20 year U.S. Treasury Constant Maturity Rates at the weekly frequency. Treasury corresponds to the Treasury maturity rate of interest. Start date denotes the first date of the yield data and the beginning of the vector autoregression estimation period. This table presents the mean, median, maximum, minimum, and standard deviation (SD) for the selected Treasury yield series. For each yield, this table presents the KPSS test statistic and its corresponding p-value. Weekly data is obtained from the FRED database of the Federal Reserve Bank of St. Louis and ranges from January 1994 through May 2005.

\begin{tabular}{|l|c|c|c|c|}
\hline \multicolumn{1}{|c|}{ Treasury } & 1 Year & 5 Year & 10 Year & 20 Year \\
\hline \multicolumn{1}{|c|}{ Start Date } & January 1994 & January 1994 & January 1994 & January 1994 \\
\hline Panel A: Rate level & & & & 6.06 \\
\hline Mean & 4.26 & 5.15 & 5.53 & 5.99 \\
\hline Median & 5.11 & 5.47 & 5.61 & 8.26 \\
\hline Maximum & 7.24 & 7.86 & 8 & 4.21 \\
\hline Minimum & 0.95 & 2.13 & 3.2 & 0.89 \\
\hline SD & 1.78 & 1.35 & 1.08 & $7.62^{* * *}$ \\
\hline KPSS Test Statistic & $6.96^{* * *}$ & $7.40^{* * *}$ & $<.54 * * * 1$ & $<01$ \\
\hline KPSS p-value & $<0.01$ & $<0.01$ & & -0.00291 \\
\hline Panel B: Rate difference & & & -0.0025 & $(-0.74)$ \\
\hline Mean & -0.00029 & -0.0019 & $-0.57)$ & -0.01 \\
\hline Median & $(-0.08)$ & $(-0.40)$ & -0.01 & 0.36 \\
\hline Maximum & 0 & -0.01 & -0.31 & -0.25 \\
\hline Minimum & 0.36 & 0.44 & 0.11 & 0.10 \\
\hline SD & -0.48 & -0.41 & 0.08 & 0.08 \\
\hline KPSS Test Statistic & 0.09 & 0.12 & $>0.1$ & $>0.1$ \\
\hline KPSS p-value & 0.39 & 0.13 & & \\
\hline
\end{tabular}

$* * *, * *$ indicate statistical significance at the 0.01 and 0.05 level, respectively

Table 2

Table 2 presents information criteria values for the Akaike Information Criterion (AIC), Hannan and Quinn Information Criterion (HQ), and the Schwarz Information Criterion (SC). The data are the differenced series of the 1 year, 5 year, 10 year, and 20 year U.S. Treasury Constant Maturity Rates at the weekly frequency. Lag corresponds to the order of the vector autoregression. Weekly interest rate data is obtained from the FRED database of the Federal Reserve Bank of St. Louis and ranges from January 1994 through May 2005.

\begin{tabular}{|c|c|c|c|c|c|}
\hline Lag & 1 & 2 & 3 & 4 & 5 \\
\hline \multicolumn{6}{|c|}{ Information Criteria } \\
\hline AIC & -24.82 & -24.83 & -24.89 & -24.87 & -24.84 \\
\hline HQ & -24.77 & -24.73 & -24.74 & -24.67 & -24.60 \\
\hline $\mathrm{SC}$ & -24.67 & -24.56 & -24.50 & -24.36 & -24.21 \\
\hline
\end{tabular}


Table 3

Table 3 presents the estimation results of a vector autoregression (VAR) model of order 1 for the differenced U.S. Treasury Constant Maturity Rates. Treasury corresponds to the Treasury maturity rate of interest. Start date denotes the first date of the yield data and the beginning of the vector autoregression estimation period. This table presents the coefficient estimates for the vector autoregression, equation-by-equation. The dependent variable in each equation is the differenced Treasury maturity rate, designated in the row titled Treasury. The independent variables in each equation are the lagged, differenced maturity rates. Tratios for testing the null hypothesis of zero magnitude are presented in parentheses. F-test statistics, the associated F-test pvalues, and the $\mathrm{R}^{2}$ are presented for each regression equation. Weekly data is obtained from the FRED database of the Federal Reserve Bank of St. Louis and ranges from January 1994 through May 2005.

\begin{tabular}{|c|c|c|c|c|}
\hline Treasury & 1 Year & 5 Year & 10 Year & 20 Year \\
\hline Start Date & January 1994 & January 1994 & January 1994 & January 1994 \\
\hline \multicolumn{5}{|l|}{ Coefficient } \\
\hline Intercept & $\begin{array}{l}-0.0006 \\
(-0.16)\end{array}$ & $\begin{array}{l}-0.0017 \\
(-0.38)\end{array}$ & $\begin{array}{l}-0.0022 \\
(-0.51)\end{array}$ & $\begin{array}{l}-0.0025 \\
(-0.64)\end{array}$ \\
\hline Treasury1YR(-1) & $\begin{array}{l}0.25 \\
(3.51)^{* * *}\end{array}$ & $\begin{array}{c}-0.07 \\
(-0.79) \\
\end{array}$ & $\begin{array}{c}-0.14 \\
(-1.60) \\
\end{array}$ & $\begin{array}{c}-0.14 \\
(-1.78) * \\
\end{array}$ \\
\hline Treasury5YR(-1) & $\begin{array}{c}0.14 \\
(1.04)\end{array}$ & $\begin{array}{c}0.34 \\
(1.91)^{*}\end{array}$ & $\begin{array}{c}0.20 \\
(1.20)\end{array}$ & $\begin{array}{c}0.16 \\
(1.07)\end{array}$ \\
\hline Treasury10YR(-1) & $\begin{array}{c}0.15 \\
(0.78) \\
\end{array}$ & $\begin{array}{c}0.24 \\
(0.94) \\
\end{array}$ & $\begin{array}{c}0.34 \\
(1.46) \\
\end{array}$ & $\begin{array}{c}0.14 \\
(0.67) \\
\end{array}$ \\
\hline Treasury20YR(-1) & $\begin{array}{l}-0.35 \\
(-2.46) * *\end{array}$ & $\begin{array}{c}-0.36 \\
(-1.90) * \\
\end{array}$ & $\begin{array}{c}-0.28 \\
(-1.60) \\
\end{array}$ & $\begin{array}{c}-0.03 \\
(-0.20) \\
\end{array}$ \\
\hline $\mathrm{R}^{2}$ & 0.1036 & 0.0661 & 0.0608 & 0.0540 \\
\hline F-test statistic & $16.90 * * *$ & $10.35 * * *$ & $9.47 * * *$ & $8.34 * * *$ \\
\hline F test $p$-value & $4.04 \mathrm{E}-13$ & $4.17 \mathrm{E}-08$ & $2.00 \mathrm{E}-07$ & $1.51 \mathrm{E}-06$ \\
\hline
\end{tabular}

$* * *, * * *$ indicate statistical significance at the $0.01,0.05$, and 0.10 level, respectively 